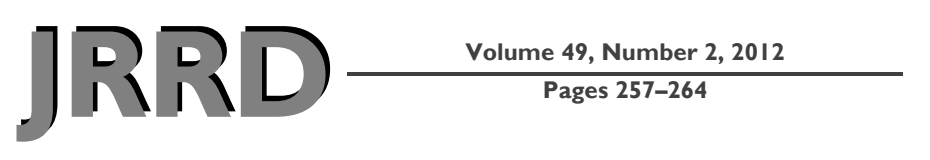

\title{
Colonoscopic lesions in veterans with spinal cord injury
}

\author{
Meheroz H. Rabadi, MD, MRCPI, FAAN; ${ }^{{ }^{*}}$ Andrea S. Vincent, PhD $^{\mathbf{2}}$ \\ ${ }^{1}$ Department of Neurology at the Oklahoma Health Sciences Center, Oklahoma City, OK; ${ }^{2}$ Center for the Study of Human \\ Operator Performance, University of Oklahoma at Norman, Norman, OK
}

\begin{abstract}
The overall goal of this observational study was to determine the type and prevalence of colonoscopic lesions encountered in veterans with traumatic spinal cord injury (SCI) and to examine their relationship to lesion level, completeness, and duration postinjury. We retrospectively reviewed the electronic charts of veterans with SCI who are regularly followed in our SCI clinic. Colonoscopy in veterans with SCI was undertaken for their gastrointestinal (GI) complaints. Of the 87 veterans with SCI, 71 who were 50 years of age or older were included in this study. Of these 71, 28 underwent colonoscopies (39.4\%). Demographic variables were matched between patients who underwent colonoscopies and those who did not for age, sex, race/ethnicity, age of onset of SCI, and duration of SCI $(p>0.05)$. The colonoscopic lesions seen in 26 (93\%) of the 28 veterans with SCI who underwent colonoscopies included diverticulae, internal hemorrhoids, and polyps. No relationship was found between colonoscopic lesion type and SCI lesion location or severity. A relationship was found between total colonoscopic lesions and duration of SCI $(p<0.001)$. Age-, sex-, and race/ethnicitymatched veterans without SCI (controls) who underwent colonoscopy for their GI complaints had more colonoscopic lesions than the veterans with SCI who underwent colonoscopies $(p<0.001)$.
\end{abstract}

Key words: bowel program, colonic cleaning, colonoscopic lesions, colonoscopy, GI complaints, matched controls, observation, rehabilitation, SCI, veterans.

\section{INTRODUCTION}

Neurogenic bowel (defined as colonic dysfunction from lack of nervous control) following a traumatic spinal cord injury (SCI) has been well studied [1-2]. In upper motor neuron type SCI lesions above the conus medullaris, supra-spinal inhibitory input is lost, hence reduced colonic motility and increased difficulty in rectal emptying [3-4]. In lower motor neuron type SCI lesions cauda equina, colorectal tone is lost and the recto-anal inhibitory reflex is decreased, leading to insensate rectal filling, progressive rectal distension, and fecal soiling [3]. Thus, bowel dysfunction is a source of distress for SCI patients and significantly associated with extensive time and assistance from healthcare providers or attendants for bowel management [5]. The diagnosis of chronic abdominal complaints in SCI patients is difficult because of changes in visceral and somatic sensation, gut motility, and voluntary motor function [6]. The most commonly reported gastrointestinal (GI) complaints leading to frequent hospitalization and influencing these patients' lifestyles are poorly localized abdominal pain, constipation, incontinence, abdominal distension, and autonomic hyperreflexia from the GI tract [5,7-8]. These complaints have been found to increase with the time following injury [7] and are related to the level of spinal injury.

Veterans Health Administration (VHA) Directive 1176 stipulates that all eligible veterans with spinal cord injury

Abbreviations: ASIA $=$ American Spinal Injury Association, $\mathrm{BMI}=$ body mass index, $\mathrm{GI}=$ gastrointestinal, $\mathrm{HDL}=$ highdensity lipoprotein, OSPS = oral sodium phosphosoda, $\mathrm{PEG}=$ polyethylene glycol, $\mathrm{PR}$ = per rectum, $\mathrm{SCI}$ = spinal cord injury, $\mathrm{T}=$ thoracic, VAMC $=$ Department of Veterans Affairs medical center, VHA = Veterans Health Administration.

*Address all correspondence to Meheroz H. Rabadi, MD, MRCPI, FAAN; Department of Veterans Affairs Medical Center, 921 NE 13th Street, Oklahoma City, OK, 73104; 405456-5298; fax: 405-456-1504. Email: rabadimh@gmail.com, meheroz.rabadi@va.gov

http://dx.doi.org/10.1682/JRRD.2011.03.0036 
and disorders be provided with a full range of care to promote and maintain health, independence, and quality of life so they can be productive individuals. Furthermore, this VHA directive stipulates that veterans between the ages of 50 and 75 should receive colon cancer screening by colonoscopy. If a screening colonoscopy finds no precancerous polyps, another screening colonoscopy is not needed for 5 to 10 years. If precancerous polyps are found, a surveillance colonoscopy will be required at least once every 2 years.

SCI patients receive fewer colonoscopies than the general population, according to a self-reported survey [9]. This lack of colonoscopy in SCI patients is due to several reasons: (1) SCI patients present with GI complaints that are different from those of the general population, (2) the presence of neurogenic bowel makes bowel preparation difficult [10], and (3) colonoscopy is technically difficult in this patient group. The purpose of this study was to determine the type and prevalence of colonoscopic lesions in veterans with SCI who were at least 50 years of age and had undergone colonoscopy for complaints of abdominal pain and discomfort and bleeding per rectum (PR).

\section{METHODS}

\section{Participants and Procedures}

Eighty-seven patients with SCI were identified based on retrospective review of the electronic medical records of veterans enrolled in the Spinal Cord Registry of a tertiary care Department of Veterans Affairs medical center (VAMC) during the 5-year study period (1/1/2005 to $12 / 31 / 2009)$. Of these 87 patients, the 71 who were 50 years or older were included in the study.

Demographic information was retrospectively collected from the review of the electronic charts and included the following: age; sex; race/ethnicity; and SCI descriptors, such as etiology (e.g., motor vehicle crash, gunshot wound, fall, diving), age at onset, time since onset, level of injury, and completeness of injury as determined by the American Spinal Injury Association (ASIA) Impairment Scale [11]. Additional risk factors examined were hypertension, diabetes mellitus, hyperlipidemia, body mass index (BMI), current smoker, and depression. Demographic and other risk factors were compared between those who had undergone colonoscopy for their GI complaints and those who did not because they had no GI complaints. Veterans with SCI and colonoscopic lesions were also compared with veterans without SCI (controls) who had colonoscopy for their GI complaints and were matched for age, sex, and race/ethnicity.

At our institution, patients took a bowel preparation class before undergoing a colonoscopy; they were informed to stop taking their iron-containing medications 7 days before the examination and antiplatelet medications and Coumadin 5 days before the examination. Two days before the examination, patients were put on a liquid diet and consumed $10 \mathrm{fl} \mathrm{oz} \mathrm{(296} \mathrm{mL)} \mathrm{of} \mathrm{magnesium}$ citrate. The day before the examination, the patients took $8 \mathrm{fl} \mathrm{oz}(240 \mathrm{~mL}$ ) of GoLytely (Braintree Laboratories; Braintree, Massachusetts) every 10 minutes and drank any clear liquid as tolerated. On the day of the examination, the patients took medicines with small sips of water. Conscious sedation was induced intravenously by $2 \mathrm{mg}$ Versed and $50 \mathrm{mg}$ fentanyl. Antispasmodic medications were used sparingly. Colonoscopy was performed by an experienced gastroenterologist using an Olympus CF180AL scope (Center Valley, Pennsylvania). SCI veterans with poor bowel preparation had their colonoscopy rescheduled for the following day; they repeated the intake of $8 \mathrm{fl} \mathrm{oz}(240 \mathrm{~mL})$ of GoLytely every 10 minutes and drank any clear liquid as tolerated. The endoscopist rated the adequacy of colonic cleaning based on the Aronchick scale [12]:

1. Excellent: Small volume of clear liquid or $>95$ percent of surface seen.

2. Good: Large volume of clear liquid covering 5 to 25 percent of the surface but $>90$ percent of surface seen.

3. Fair: Some semisolid stool that could be suctioned or washed away but $>90$ percent of surface seen.

4. Poor: Semisolid stool that could not be suctioned or washed away and $<90$ percent of surface seen.

5. Inadequate: Repreparation needed.

Abnormal lesions encountered were photographed and biopsied. Veterans were informed of their colonoscopy findings and biopsy result based on pathology report.

For this study, prevalence was defined as the number of cases (e.g., persons with SCI, colonoscopic lesions) that occurred in this SCI population within a specific period of time [13]. Prevalence was based on the number of persons who visited the VAMC SCI outpatient clinic from 1/1/2005 to 12/31/2009 inclusive. 


\section{Statistical Analysis}

Data were analyzed using SAS (SAS System for Windows, version 9.1, SAS Institute, Inc; Cary, North Carolina). Data are expressed as mean \pm standard deviation when normally distributed (Table 1). Interval data were compared between groups (with/without colonoscopy and with/without SCI) using a two-tailed Student's $t$-test (BMI, high-density lipoprotein [HDL]) or a Wilcoxon-Mann-Whitney test (age, age at injury onset, years since injury, total cholesterol, low-density lipoprotein, and triglycerides) according to

Table 1.

Comparison of study variables between patient groups with spinal cord injury (SCI) based on presence or absence of colonoscopy. (Data shown as mean \pm standard deviation, $n$ (\%), or $n$, as appropriate.)

\begin{tabular}{|c|c|c|c|c|}
\hline Variable & $\begin{array}{c}\text { Total } \\
(N=71)\end{array}$ & $\begin{array}{c}\text { Colonoscopy } \\
(n=28)\end{array}$ & $\begin{array}{c}\text { No Colonoscopy } \\
(n=43)\end{array}$ & $p$-Value \\
\hline Age (yr) & $62.2 \pm 7.8$ & $61.9 \pm 7.8$ & $62.3 \pm 7.8$ & $0.84^{*}$ \\
\hline Sex (Male:Female) & $70: 1$ & $27: 1$ & $43: 0$ & $0.39^{\dagger}$ \\
\hline Race/Ethnicity $(n=71)$ & & & & $0.45^{\dagger}$ \\
\hline White & 59 & $25(89)$ & $34(81)$ & \\
\hline Black & 8 & $3(10)$ & $5(12)$ & \\
\hline American Indian & 3 & 0 & $3(7)$ & \\
\hline Age at Onset of SCI (yr) & $36.1 \pm 14.4$ & $33.6 \pm 14.1$ & $37.8 \pm 14.5$ & $0.24^{*}$ \\
\hline Duration Since SCI (yr) & $27.6 \pm 15.8$ & $29.9 \pm 15.3$ & $26.1 \pm 16.1$ & $0.34^{*}$ \\
\hline Spinal Level of Injury & & & & $0.09^{\dagger}$ \\
\hline Cervical & 35 & $11(39)$ & $24(56)$ & \\
\hline Thoracic & 28 & $11(39)$ & $17(40)$ & \\
\hline Lumbosacral & 8 & $6(21)$ & $2(5)$ & \\
\hline ASIA Impairment Scale & & & & $0.75^{\dagger}$ \\
\hline $\mathrm{A}$ & 28 & $10(36)$ & $18(42)$ & \\
\hline B & 9 & $3(10)$ & $6(14)$ & \\
\hline $\mathrm{C}$ & 16 & $8(28)$ & 8 (19) & \\
\hline $\mathrm{D}$ & 16 & $7(25)$ & $9(21)$ & \\
\hline $\mathrm{E}$ & 2 & 0 & $2(5)$ & \\
\hline Etiology of SCI & & & & $0.41^{\dagger}$ \\
\hline Motor Vehicle Accident & 32 & $11(39)$ & $21(48)$ & \\
\hline Gunshot & 11 & $4(14)$ & $7(16)$ & \\
\hline Fall & 17 & $7(25)$ & $10(23)$ & \\
\hline Diving & 2 & 0 & $2(5)$ & \\
\hline Others $^{\ddagger}$ & 9 & $6(21)$ & $3(7)$ & \\
\hline \multicolumn{5}{|l|}{ Risk Factors } \\
\hline Hypertension $(n=69)$ & $40(58)$ & $21(75)$ & $19(46)$ & 0.02 \\
\hline Diabetes Mellitus & $23(32)$ & $12(43)$ & $11(26)$ & 0.13 \\
\hline Hyperlipidemia $(n=59)$ & $36(61)$ & $19(79)$ & $17(49)$ & 0.02 \\
\hline BMI (Normal: 19-25) & $28.0 \pm 7.6$ & $30.3 \pm 7.0$ & $26.6 \pm 7.7$ & $0.05^{*}$ \\
\hline Current Smoker $(n=71)$ & $30(43)$ & $10(36)$ & $20(48)$ & 0.32 \\
\hline Depression & $34(48)$ & $17(61)$ & $17(40)$ & 0.08 \\
\hline \multicolumn{5}{|l|}{ Biomedical Factors $(n=68)$} \\
\hline Total Cholesterol $(120-200 \mathrm{mg} / \mathrm{dL})$ & $161.7 \pm 38.8$ & $158.0 \pm 33.5$ & $164.0 \pm 42.0$ & $0.55^{*}$ \\
\hline LDL $(80-130 \mathrm{mg} / \mathrm{dL})$ & $102.2 \pm 36.7$ & $96.8 \pm 34.3$ & $105.6 \pm 38.1$ & $0.34^{*}$ \\
\hline HDL (35-70 mg/dL) & $37.6 \pm 10.3$ & $34.5 \pm 9.7$ & $39.6 \pm 10.3$ & $0.04^{*}$ \\
\hline Triglycerides (30-200 mg/dL) & $152.2 \pm 119.4$ & $187.1 \pm 157.1$ & $130.7 \pm 83.7$ & $0.10^{*}$ \\
\hline $\begin{array}{l}\text { "Student's } \text {-test. } \\
{ }^{*} \text { Fisher exact test. } \\
{ }^{\ddagger} \text { Assaults and non-motor vehicle accidents. } \\
\text { ASIA = American Spinal Injury Association, }\end{array}$ & nesc indoy L & 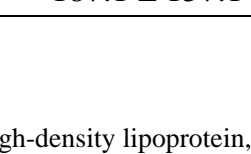 & 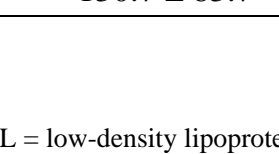 & \\
\hline
\end{tabular}


normality of distribution; categorical data were compared using chi-square or Fisher Exact test when appropriate. Severity of SCI in relation to colonoscopic lesions was examined using Fisher Exact test. Logistic regression (for categorical outcome variables) and analysis of covariance (for continuous outcome variables) were conducted to determine whether differences could be accounted for by age and duration since SCI. Significance level was set at $p<0.05$ for all analyses.

\section{RESULTS}

In this retrospective chart-review study, 28 (39.4\%) of 71 SCI patients above age 50 had a colonoscopy for their GI complaints; colonoscopic lesions were found in 26 (93\%) of these patients during the 5-year study period. The most frequent lesions found were internal hemorrhoids (13 cases), polyps (11 cases), and diverticulae (10 cases). The polyps were either adenomatous or hyperplastic on histology. Other incidental lesions found were colonic/rectal ulcers, colitis, and angioectasias. There were 2 normal colonoscopies; none of the 28 patients had colon cancer. During this study period, the colonoscopy SCI group was hypertensive (75\%), hyperlipidemic (79\%), had a higher BMI ( $p=0.05)$, and had a lower HDL level $(p=0.04)$ compared with the non-colonoscopy SCI group. These differences persisted for hyperlipidemia $(p=0.03)$ and hypertension $(p=0.02)$ after controlling for age and duration since SCI; however, these group differences were not retained for BMI and HDL ( $p=0.05$ and 0.06 , respectively).

The proportion of colonoscopic lesions both individually and collectively (total 41 lesions) were not related to SCI lesion level ( $p=0.17$ ) (Table 2) or to the completeness of the lesion as per ASIA Impairment Scale score $(p=0.29)$ (Table 3). However, a significant relationship was found between the proportion of total colonoscopic lesions (41 lesions) and the duration of SCI: $<5$ years $=2$ percent, $5-10$ years $=10$ percent, $11-20$ years $=12$ percent, $>20$ years $=$ 76 percent $(p<0.001)$.

For the given GI complaints of abdominal pain, discomfort, and bleeding PR for which colonoscopy was undertaken, significantly more colonic polyps $(p<0.001)$ and total colonic lesions were found in the matched veterans without SCI (control) than in the SCI colonoscopy group, $t(54)=3.5, p<0.001$. This difference between these groups in number of colonic lesions disappeared
Table 2.

Colonoscopic findings relative to spinal cord injury (SCI) lesion level. (Data shown as number of patients who had colonoscopic findings; some had multiple lesions and, thus, may be counted more than once.)

\begin{tabular}{lcccc}
\hline \multicolumn{1}{c}{$\begin{array}{c}\text { Colonoscopic } \\
\text { Lesion }\end{array}$} & $\begin{array}{c}\text { Cervical } \\
(\boldsymbol{n}=\mathbf{1 1})\end{array}$ & $\begin{array}{c}\text { Thoracic } \\
(\boldsymbol{n}=\mathbf{1 1})\end{array}$ & $\begin{array}{c}\text { Lumbosacral } \\
(\boldsymbol{n}=\mathbf{6})\end{array}$ & $\boldsymbol{p}$-Value \\
\hline Diverticulae & 4 & 4 & 2 & 0.99 \\
Internal Hemorrhoids & 7 & 3 & 3 & 0.25 \\
Polyps & 3 & 6 & 2 & 0.48 \\
Colonic Cancer & 0 & 0 & 0 & - \\
Normal & 1 & 1 & 0 & 0.99 \\
Other $^{*}$ & 1 & 2 & 2 & 0.49 \\
\hline Total & 16 & 16 & 9 & \\
\hline
\end{tabular}

Note: Fisher exact test within finding across SCI lesion level.

${ }^{*}$ Ulcers (3), colitis, and angioectasia.

Table 3.

Colonoscopic findings relative to American Spinal Injury Association (ASIA) Impairment Scale level. (Data shown as number of patients who had colonoscopic findings; some had multiple lesions and, thus, may be counted more than once.)

\begin{tabular}{lccccc}
\hline \multicolumn{1}{c}{$\begin{array}{c}\text { Colonoscopic } \\
\text { Lesion }\end{array}$} & $\begin{array}{c}\text { A } \\
(\boldsymbol{n}=\mathbf{1 0})\end{array}$ & $\begin{array}{c}\text { B } \\
(\boldsymbol{n}=\mathbf{3})\end{array}$ & $\begin{array}{c}\mathbf{C} \\
(\boldsymbol{n}=\mathbf{8})\end{array}$ & $\begin{array}{c}\mathbf{D} \\
(\boldsymbol{n}=\mathbf{7})\end{array}$ & $\boldsymbol{p}$-Value \\
\hline Diverticulae & 2 & 3 & 2 & 3 & 0.09 \\
Internal Hemorrhoids & 2 & 0 & 5 & 6 & 0.01 \\
Polyps & 5 & 3 & 2 & 1 & 0.06 \\
Colonic Cancer & 0 & 0 & 0 & 0 & - \\
Normal & 1 & 0 & 1 & 0 & 0.99 \\
Other & 2 & 0 & 3 & 0 & 0.32 \\
\hline Total & 12 & 6 & 13 & 10 & \\
\hline
\end{tabular}

Note: Fisher exact test within finding across ASIA level.

after controlling for age, $F(1,52)=1.22, p=0.27$. The quality of colonic preparation was similar in both these groups $(p=0.05)$ (Table 4$)$.

\section{DISCUSSION}

This study is the first to look at the prevalence of colonoscopic lesions in veterans with SCI who underwent colonoscopy for their GI complaints. In this study, 39 percent of the veterans with SCI who were older than 50 underwent colonoscopy. The prevalence of colonoscopic lesions in these veterans was 93 percent. The most common colonoscopic lesions were diverticulae, polyps, and internal hemorrhoids. The number of colonoscopic lesions progressively increased with the duration of SCI. Stone et al. report similar findings in their study of 127 patients with SCI [7]. They found that the percentage of patients with symptomatic GI complaints increased progressively 
Table 4.

Average number of lesion types in veterans with and without SCI (mean \pm standard deviation or $n$ ).

\begin{tabular}{lccc}
\hline \multicolumn{1}{c}{ Variable } & $\begin{array}{c}\text { SCI } \\
\text { Patients } \\
(\boldsymbol{n}=\mathbf{2 8})\end{array}$ & $\begin{array}{c}\text { Non-SCI } \\
\text { Patients } \\
(\boldsymbol{n}=\mathbf{2 8})\end{array}$ & $\boldsymbol{p}$-Value \\
\hline Age (yr) & $61.9 \pm 7.8$ & $61.9 \pm 7.4$ & 0.99 \\
Sex (Male:Female) & $27: 1$ & $27: 1$ & 0.99 \\
Race/Ethnicity & $25: 3$ & $25: 3$ & 0.99 \\
$\quad$ (White:Black) & $1.5 \pm 0.8$ & $2.1 \pm 0.7$ & $<0.001^{*}$ \\
Lesion & 10 & 14 & $0.42^{\dagger}$ \\
$\quad$ Diverticulae & 13 & 19 & $0.18^{\dagger}$ \\
Internal Hemorrhoids & 13 & 27 & $<0.001^{\dagger}$ \\
Colonic Polyps & 0 & 0 & - \\
Colonic Cancer & 2 & 0 & $0.34^{\dagger}$ \\
Normal & 5 & 0 & $0.02^{\dagger}$ \\
Other & & & $0.05^{\dagger}$ \\
Preparation Quality & 20 & 23 & \\
$\quad$ Good & 6 & 1 & \\
Fair & 0 & 2 & \\
Poor & 2 & 2 & \\
$\quad$ Unknown & & & \\
${ }^{*}$ Student’s $t$-test. & & & \\
${ }^{\dagger}$ Fisher exact test. & &
\end{tabular}

with the number of years postinjury (44\% in those who were $>20$ years postinjury). In Han et al.'s study [14], the incidence of colonoscopic lesions was 52 percent compared with 93 percent in our study. This result was due mainly to a higher percentage of normal colonoscopies (48\%) and fewer patients with an SCI duration of 20+ years $(n=3)$ in Han et al. [14], compared with only 2 percent normal colonoscopies and more patients with an SCI duration of $20+$ years $(n=20)$ in our study. The presence of colonoscopic lesions suggests that veterans with SCI need to be reminded to use a daily bowel regimen to reduce GI problems.

In this study, the lesion level and completeness of SCI did not influence the incidence of colonoscopic lesions. We had expected that lesion level and completeness of injury would influence the incidence of colonoscopic lesions, with patients with cervical spine-level SCI and ASIA A severity having the most colonoscopic lesions. That this hypothesis was not upheld was an interesting finding, given that lesion level is considered to be an important determinant of defecation control and its consequences. Vallès et al. [2], in their study of 54 patients with SCI, found that patients with injuries above thoracic ( $\mathrm{T}$ ) 7 were frequently constipated $(86.0 \%)$ with significant defecatory difficulty compared with patients with injuries below T7; those patients with injuries below T7 with pre- served sacral reflexes were less constipated (50.0\%), while those with absent sacral reflexes had greater fecal incontinence (7.2\%).

The quality of bowel preparation has been shown to influence colonoscopic findings. Bowel preparation has been found to be suboptimal in 80 percent of SCI patients as a result of inherent neurogenic bowel [10], resulting in poor visualization on colonoscopy. No bowel cleaning agent singly or in combination has been found to adequately prepare the bowel for colonoscopy in most patients with SCI. Ancha et al., in their study of 36 patients with SCI (with an estimated glomerular filtration rate $>60 \mathrm{~mL} / \mathrm{min} / 1.73 \mathrm{~m}^{2}$ when randomized to polyethylene glycol [PEG] $[n=12]$ or oral sodium phosphosoda [OSPS] [ $n=11]$, or combined PEG+OSPS $[n=13]$ ) found that 73 percent of subjects had unacceptable colonic cleaning [15]. This issue was not found in our study because the colonoscopic procedure was aborted in SCI veterans with poor bowel preparation and rescheduled for the next day after an acceptable bowel preparation in order to allow visualization to the cecum. Veterans without SCI (control) had more polyps and total colonoscopic lesions than SCI veterans for given similar GI complaints. This difference between the two groups disappeared when controlled for age. Surprisingly, no colonic cancer was found in either group despite a reported two- to sixfold increase age-adjusted incidence rate in men with myelopathy compared with the general male population [16]. The prompt work-up of SCI veterans with GI complaints (including early colonoscopy with polyp excision) may have prevented future development of colon cancer.

Veterans with SCI undergoing colonoscopy in this study were more frequently hypertensive and hyperlipidemic, with raised BMI and reduced HDL levels. This finding was not surprising because these veterans were older (61.9 \pm 7.8 years) and more prone to developing vascular risk factors due to their sedentary lifestyles [17]. Increased incidence of hypertension, but not diabetes mellitus, has been reported in SCI patients [18]. Similarly, low HDL level in SCI patients have been reported by several investigators [19-20] and levels $\leq 35 \mathrm{mg} / \mathrm{dL}$ have been recognized as an independent risk factor for coronary artery disease, a leading cause of mortality in chronic SCI patients [21]. In this study, multiple regression analysis showed that HDL levels were significantly related to BMI ( $b=0.95, t=3.47, p=0.002)$, with HDL levels increasing with increases in BMI.

The present results should be interpreted in light of a number of limitations. First, this study was limited to the 
veteran population, so it may not be generalizable to the general population. Moreover, the population of veterans from which the sample was drawn consisted predominantly of men (only 1 woman) who were heavy smokers and had easy access to quality care. Second, the sample size was rather small and may not have been able to detect significant differences between groups. Third, this was a retrospective analysis of the computerized data of veterans with SCI. Despite these limitations, the completeness of the data captured by the standardized SCI registry provides a rich data set for better understanding colonoscopic lesions in the veteran population with SCI.

\section{CONCLUSIONS}

Our study found that (1) the prevalence of colonoscopic lesions in veterans with traumatic SCI was high (93\%); (2) the lesion types were mainly diverticulae, internal hemorrhoids, and polyps; and (3) the incidence of total colonoscopic lesions increased with age in groups of veterans with and without SCI who had GI complaints. Colonoscopy was undertaken in 39 percent of the veterans with SCI who were over age 50 mainly because of their GI complaints, suggesting that this is a safe procedure. It also suggests the need for clinicians to repeatedly remind veterans of the benefits of adhering to a daily bowel care program to help deal with their GI complaints, because such GI problems have been found to negatively affect patients' quality of life and limit their ability to live independently [5].

\section{ACKNOWLEDGMENTS}

\author{
Author Contributions: \\ Study concept and design: M. H. Rabadi. \\ Acquisition of data: M. H. Rabadi. \\ Analysis and interpretation of data: M. H. Rabadi, A. S. Vincent. \\ Drafting of manuscript: M. H. Rabadi, A. S. Vincent. \\ Critical revision of manuscript for important intellectual content: \\ M. H. Rabadi, A. S. Vincent. \\ Statistical analysis: A. S. Vincent. \\ Study supervision: M. H. Rabadi.
}

Financial Disclosures: The authors have declared that no competing interests exist.

Funding/Support: This material was unfunded at the time of manuscript preparation.

Additional Contributions: Dr. Rabadi is now with the Oklahoma City VAMC.
Institutional Review: Local institutional review board for human subjects research and local Department of Veterans Affairs Research and Development Committee approval were obtained for the study.

Participant Follow-Up: The authors do not plan to inform participants of the publication of this study.

\section{REFERENCES}

1. Fajardo NR, Pasiliao RV, Modeste-Duncan R, Creasey G, Bauman WA, Korsten MA. Decreased colonic motility in persons with chronic spinal cord injury. Am J Gastroenterol. 2003;98(1):128-34. [PMID: 12526948] http://dx.doi.org/10.1111/j.1572-0241.2003.07157.x

2. Vallès M, Vidal J, Clavé P, Mearin F. Bowel dysfunction in patients with motor complete spinal cord injury: Clinical, neurological, and pathophysiological associations. Am J Gastroenterol. 2006;101(10):2290-99. [PMID: 17032195] http://dx.doi.org/10.1111\%2Fj.1572-0241.2006.00729.x

3. Craggs MD, Balasubramaniam AV, Chung EA, Emmanuel AV. Aberrant reflexes and function of the pelvic organs following spinal cord injury in man. Auton Neurosci. 2006; 126-127:355-70. [PMID: 16731049]

4. Krogh K, Mosdal C, Gregersen H, Laurberg S. Rectal wall properties in patients with acute and chronic spinal cord lesions. Dis Colon Rectum. 2002;45(5):641-49.

[PMID: 12004214] http://dx.doi.org/10.1007\%2Fs10350-004-6261-6

5. Glickman S, Kamm MA. Bowel dysfunction in spinal-cordinjury patients. Lancet. 1996;347(9016):1651-53.

[PMID: 8642958] http://dx.doi.org/10.1016/S0140-6736(96)91487-7

6. Longo WE, Ballantyne GH, Modlin IM. The colon, anorectum, and spinal cord patient. A review of the functional alterations of the denervated hindgut. Dis Colon Rectum. 1989;32(3):261-67. [PMID: 2646085] http://dx.doi.org/10.1007/BF02554543

7. Stone JM, Nino-Murcia M, Wolfe VA, Perkash I. Chronic gastrointestinal problems in spinal cord injury patients: A prospective analysis. Am J Gastroenterol. 1990;85(9):1114-19. [PMID: 2389723]

8. Krogh K, Nielsen J, Djurhuus JC, Mosdal C, Sabroe S, Laurberg S. Colorectal function in patients with spinal cord lesions. Dis Colon Rectum. 1997;40(10):1233-39. [PMID: 9336119]

9. Johnston MV, Diab ME, Chu BC, Kirshblum S. Preventive services and health behaviors among people with spinal cord injury. J Spinal Cord Med. 2005;28(1):43-54. [PMID: 15832903]

10. Barber DB, Rogers SJ, Chen JT, Gulledge DE, Able AC. Pilot evaluation of a nurse-administered carepath for 
successful colonoscopy for persons with spinal cord injury. SCI Nurs. 1999;16(1):14-15,20. [PMID: 10347539]

11. Young W. Spinal Cord Injury Levels \& Classification [Internet]. Spinal Cord Injury Information Pages; [updated 2010 Jan 4]. Available from:

http://www.sci-info-pages.com/levels.html

12. Aronchick CA, Lipshutz WH, Wright SH, Dufrayne F, Bergman G. A novel tableted purgative for colonoscopic preparation: Efficacy and safety comparisons with Colyte and Fleet Phospho-Soda. Gastrointest Endosc. 2000;52(3): 346-52. [PMID: 10968848] http://dx.doi.org/10.1067\%2Fmge.2000.108480

13. Sackett DL, Straus SE, Richardson WS, Rosenberg WMC, Haynes RB. Evidence-based medicine: How to practice and teach EBM. 2nd ed. London (UK): Churchill Livingstone; 2000.

14. Han SJ, Kim CM, Lee JE, Lee TH. Colonoscopic lesions in patients with spinal cord injury. J Spinal Cord Med. 2009; 32(4):404-7. [PMID: 19777861]

15. Ancha HR, Spungen AM, Bauman WA, Rosman AS, Shaw S, Hunt KK, Post JB, Galea M, Korsten MA. Clinical trial: The efficacy and safety of routine bowel cleansing agents for elective colonoscopy in persons with spinal cord injury-A randomized prospective single-blind study. Aliment Pharmacol Ther. 2009;30(11-12):1110-17. [PMID: 19769634$]$ http://dx.doi.org/10.1111\%2Fj.1365-2036.2009.04147.x

16. Frisbie JH, Chopra S, Foo D, Sarkarati M. Colorectal carcinoma and myelopathy. J Am Paraplegia Soc. 1984;7(2): 33-36. [PMID: 6726220]

17. Wahman K, Nash MS, Westgren N, Lewis JE, Seiger A, Levi R. Cardiovascular disease risk factors in persons with paraplegia: The Stockholm spinal cord injury study. J Reha- bil Med. 2010;42(3):272-78. [PMID: 20419873]

http://dx.doi.org/10.2340\%2F16501977-0510

18. Yekutiel M, Brooks ME, Ohry A, Yarom J, Carel R. The prevalence of hypertension, ischaemic heart disease and diabetes in traumatic spinal cord injured patients and amputees. Paraplegia. 1989;27(1):58-62. [PMID: 2784200]

19. Bauman WA, Spungen AM, Zhong YG, Rothstein JL, Petry C, Gordon SK. Depressed serum high density lipoprotein cholesterol levels in veterans with spinal cord injury. Paraplegia. 1992;30(10):697-703. [PMID: 1448297] http://dx.doi.org/10.1038\%2Fsc.1992.136

20. Krum H, Howes LG, Brown DJ, Ungar G, Moore P, McNeil JJ, Louis WJ. Risk factors for cardiovascular disease in chronic spinal cord injury patients. Paraplegia. 1992;30(6): 381-88. [PMID: 1635786] http://dx.doi.org/10.1038\%2Fsc.1992.87

21. Anderson KM, Castelli WP, Levy D. Cholesterol and mortality. 30 years of follow-up from the Framingham study. JAMA. 1987;257(16):2176-80. [PMID: 3560398] http://dx.doi.org/10.1001\%2Fjama.257.16.2176

Submitted for publication March 8, 2011. Accepted in revised form June 20, 2011.

This article and any supplementary material should be cited as follows:

Rabadi MH, Vincent AS. Colonoscopic lesions in veterans with spinal cord injury. J Rehabil Res Dev. 2012; 49(2):257-64.

http://dx.doi.org/10.1682/JRRD.2011.03.0036

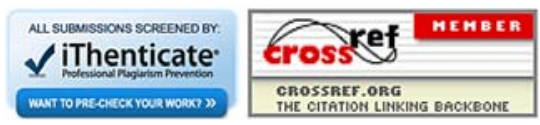


